\title{
LEADERSHIP IN MERGER AND ACQUISITION SITUATION: A CASE REVIEW OF LUFTHANSA SERVICE GmbH (LSG) and Sky Chefs Inc.
}

\author{
Lufina Mahadewi \\ Sampoerna School of Business
}

This article proposes a relation and linkage between leadership aspects and their involvement in managing the soft factor issues post-Merger and Acquisition (M\&A) to achieve the best outcome. The relation and linkage is drawn from the analysis of $M \& A$ and leadership aspects. The analysis shows that leadership plays a significant role as a fundamental mechanism in successful change. The author proposes that leadership is one of the key success factors in overall M\&A process. This view is supported by consideration of Lufthansa Service GmbH (LSG) and Sky Chefs Inc case study.

Keywords:

M\&A, Leadership, Post M\&A Integration, 7s McKinsey, Soft Factors, Change Management. 


\section{INTRODUCTION}

Merger and acquisition (M\&A) approach is often implemented to maximize the new firm's share value.

Despite that goal, there are some fundamental objectives underlying the M\&A transaction, which include growth or diversification, synergy, increased managerial skill or technology, tax considerations, defense against takeover, hubris, and agency problems. Mainly, the rationalized objective and stated motive of M\&A is to achieve synergistic benefit which includes operating and financial synergy.

A lot of studies have been done to evaluate the performance of M\&A process such as Mercer (1996), Coopers \& Lybrand (1996), A.T. Kearney (1998), KPMG (1999 and 2001), and McKinsey (2000). They documented an approximately 50-80\% failure rate in which the definition of failure ranges from no net growth to inferior stock performance relative to industry. The failure shows that M\&A companies could not exploit the synergies coming from a newly formed company or unit by several indications of lower share price, profitability decline, market share loss, lack of support from stakeholder, loss of key employees' retention, and a slope in customer and supplier relationship. The most common reason for failure in M\&A is associated with lack of focus on soft factors or personnel issues and generally is not from external factors such as market, competition, high purchase premium, degree of relation of both organizations, and excessive leverage. Personnel problems are viewed as one of the main reasons for the disappointing financial results of more than half of M\&A.

The soft factors which are described in 7s McKinsey model are Style or Culture, Staff, Skills, and Shared values. The lack of consideration of soft factors may reflect potentially to cultural clash, increment in employees' uncertainty and stress level, and also low perceptions of the organization's trustworthiness and employees' commitment during post M\&A integration process. The post M\&A integration process relates to complex tasks and activities by having time sensitive issues associated with the speed of integration. The Human Resource (HR) due diligence is essentially needed as proactive problem solving of soft factor issues that may arise during the integration process. It can be used as an early process to address the key decisions in people issues which will help in delivering higher speed of integration. Generally, M\&A general due diligence does not focus on HR, a study has shown that only one-third of all acquisitions perform due diligence of $\mathrm{HR}$ and, by and large do so only in a cursory manner and less than $10 \%$ of all buyers performs serious HRrelated due diligence. The negligence of $\mathrm{HR}$ due diligence is generally caused by undermining its importance compared to financial issues or other strategic M\&A management, and also by the perception that personnel issues cannot be managed and are difficult to be assessed or measured.

Traditionally, the acquiring company most likely tries to create change by some extent of imposition to the acquired company. This might be done without adequate assessment of the differences in soft factors of merging companies.

Post M\&A integration often deals with significant transformational changes of merging companies in terms of development ,communication, implementation, and harmonization of a newly shared vision, strategic objective, corporate culture, and also combination of companies best value practices. The transformational change is accentuated on facilitating role of leadership in providing guidance of change cohesively, 
and also in terms of removing barriers for the success of M\&A transaction.

The author suggests that leadership is important to effectively manage all the soft factors in post M\&A integration. Leadership plays a significant role during transformational changes in M\&A as a fundamental mechanism in dealing with the change. According to studies of successful integration project, leadership is one of the crucial factors for success in post M\&A integration. Successful M\&A requires more than just effective management of M\&A strategy and activities. It goes through by developing vision of the future, communicating the vision through the people, creating commitment within organizational members, engaging cultural factors, and fostering management relationships and operational guidance, not only focusing on managing the value creation, but also on inspiring and influencing whole members towards the achievement of the synergistic benefit of M\&A.

To look inside the attributing explanation for the optimal outcome of M\&A process, the Author tries to analyze the role of leadership in managing the soft factors of M\&A process in order to accomplish optimal synergies and benefits of M\&A transaction.

\section{ANALYTICAL FRAMEWORK}

The author uses an analytical framework as drawn in Figure 1. The author tries to draw the relation among aspects of M\&A, critical success factor of M\&A integration process, and aspects of leadership, and identify the important role of leadership in M\&A.

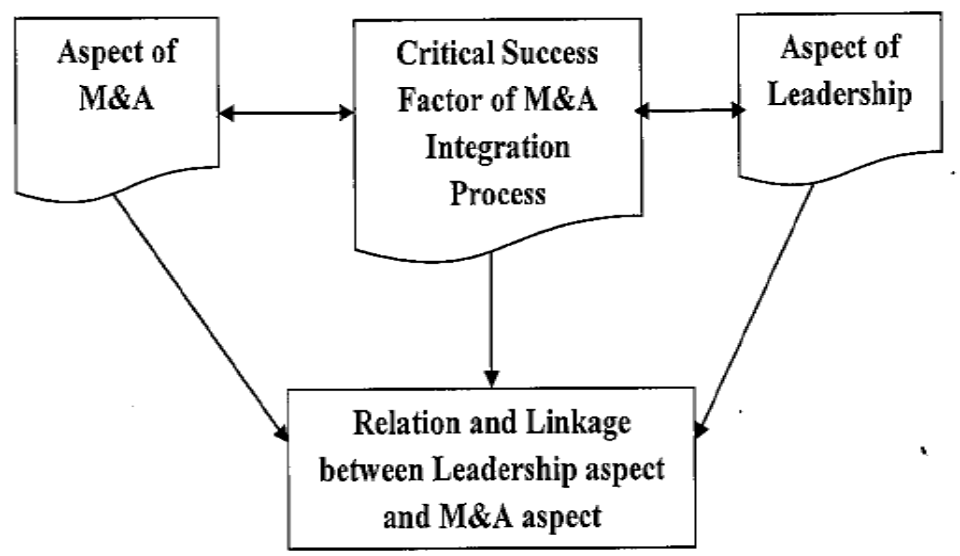

Figure 1.

Analytical Framework

\section{ANALYSIS}

\subsection{Aspects of M\&A}

\subsubsection{M\&A Trend}

M\&A activities have shown an increasing worldwide trend in recent years. The driving forces of the pace are various related to the profit recovery from economic crisis or increasing economic growth; cheap financing or reinforcement in stock prices; forces of environment change in area of globalization, innovation, competitive edge, and technology development; higher shareholders and investor confidence of 
M\&A activity; strong financial objective and commence of new strategic opportunities from industry consolidation, lower defense against takeover, and M\&A premium level increment in recent years.

The explanation of market trends and highlights of M\&A activities below can be seen on the Figure 2. which contains figures of regional distribution of M\&A activity, global M\&A volume, stock used as consideration, and average acquisition premium.

There are some market trends and some highlights of M\&A activity in the first half of 2005, which are:

a. \$1.393 trillion of global announced merger activity in 2005 year-to-date with 34\% increase year-over-year. b.16 deals greater than $\$ 10$ billion, 20 largest accounted for $27 \%$ of overall volume.

c. Bulk of M\&A activity clustered in North America (48\% of total).

d. 7 of the 10 largest M\&A deals announced through year-to-date had targets domiciled in North America, 2 in Europe and one in Japan.

e. In 2005 year to date, 39\% stock is used as a consideration in which the use of stock in transactions is leveled to the 5 year historical average.

f. Acquisition premium averaged 27\%, slightly above those in 2004. Premium over the last few years declined by $49 \%$ at the market's peak in 1999 and 2000.

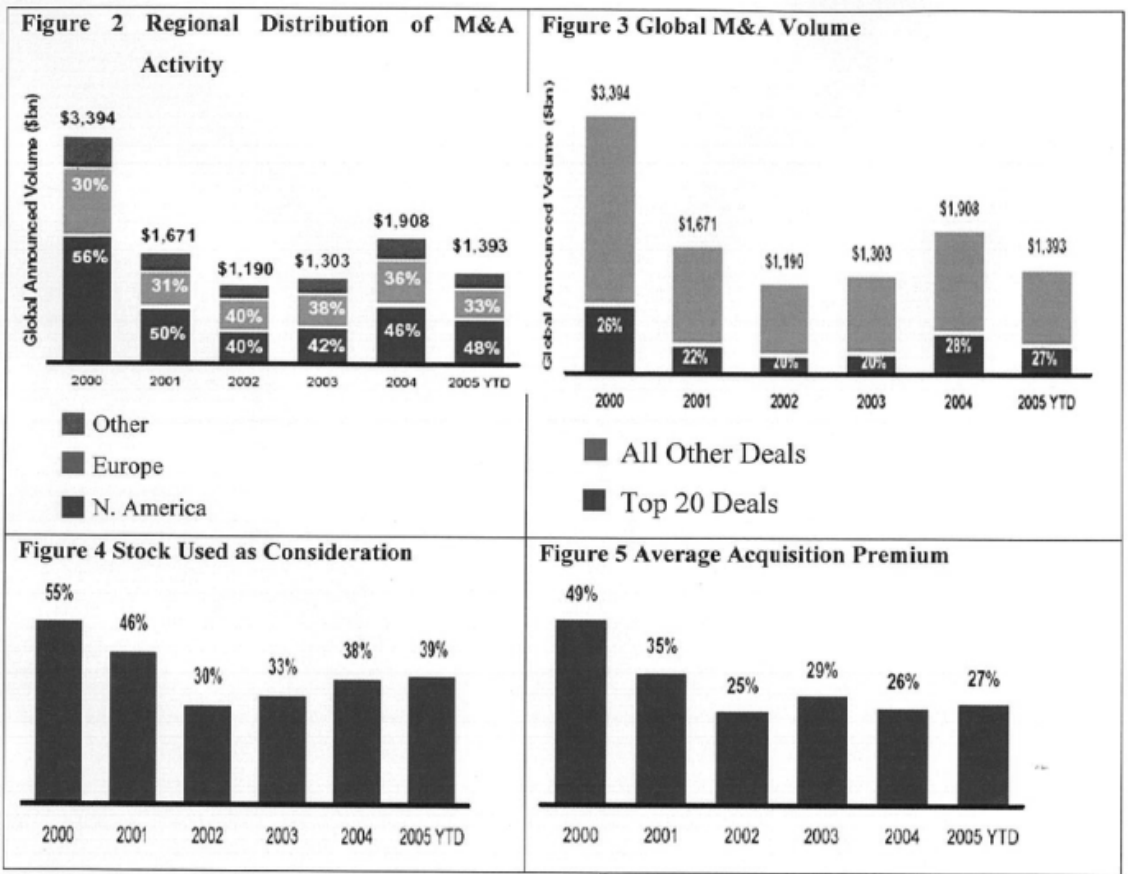

Source: Frank Richter (2007) : Goldman Sachs?

Figure 2.

M\&A Highlights Trends First Half 2005

The figure 3. describes the German market M\&A volume and the number of 
transactions as a percentage of total volume of Europe's transactions and as a percentage of German Market Capitalization. The figure shows an increasing trend from year 2003 to year 2006.

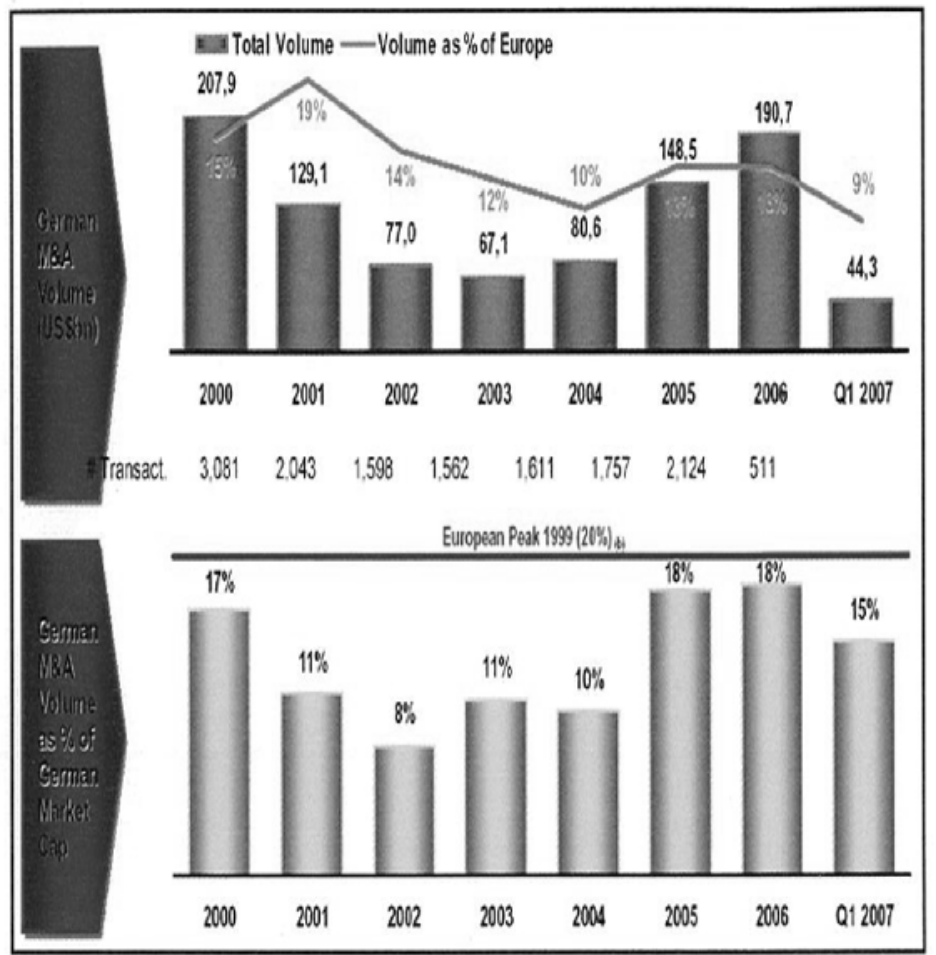

a) Excluding VW-Porsche tender offer with an Enterprise Value of US\$95.5bn.

b) Q1 annualized

Source: Frank Richter (2007): Thomson Financial Securities Data

Figure 3.

German Market M\&A Volume and Number of Transactions

M\&A becomes the key factor in business reorganization change where the number of corporate M\&A has increased sharply over the recent years triggered by the rise in number of buyers and capital and speed in market penetration. The consideration of the needs of synergy and the needs to adapt to the environment changes lead to the structural form of M\&A.

To see the pace of M\&A activity in the future, the author considers the Endgames research from A.T. Kearney
(2001) where the model enables prediction of upcoming consolidations, future mergers, and industry departures of 20 years in the future in which there are positive trends of an increasingly rapid pace of merger activity and also trends of bigger merger premiums which are built into stock prices, or to be more specific, it predicts that industry consolidations will correlate nearly $80 \%$ with the rise in global stock indices, which are predicted to run at about $300 \%$ over the next 10 years. 
Based on the Endgames model, the author considers that merger trends are going to increase significantly in the future correlated with the increment in stock prices in the future.

\subsubsection{M\&A Motivation}

The objective of maximizing the shareholder value in the form of M\&A transaction rather than in organic growth acceleration is reflected from the business time and effort saving considerations. By acquiring other company that has a high degree of relatedness in scope of business or even less degree, it is expected that goal of optimizing general business management can be achieved effectively and efficiently.

Below are some literature studies which examined the main reasons of $M \& A$ occurrence:

a.Eun, Kolodny, and Scheraga (1996): They tested the synergy hypothesis for crossborder acquisitions using a sample of foreign acquisitions of US firms during 1979-1990 and their findings indicate that cross-border takeovers are generally synergy-creating activities.

b.Seth, Song, and Pettit (2000): They found that the synergy hypothesis is the predominant explanation for their sample of foreign acquisitions of U.S. firms.

c. Mulherin and Boone (2000): They studied the acquisition and divestiture activity of a sample of 1305 firms from 59 industries during 1990 and 1999 period. They found that the symmetric, positive wealth effects for acquisitions and divestitures are consistent with a synergistic benefit for both forms of restructuring.

d.Halil Kiymaz and H. Kent Baker (2004): The study used the sample of largest M\&A activity in US firms between period 1989 and 2003 that investigated the correlation among target, acquirer, and total gains to distinguish among synergy, agency, and hubris as motives of mega mergers. The synergy, agency, and hubris hypothesis implies that correlation between target and total gains are positive, negative, and zero, and the empirical evidence supported synergy as the primary motive for mega mergers where target and total gains are positively correlated with both positive and negative measured total gains.

Based on those literature studies above, the author considers that M\&A is mainly focused on achieving the synergistic benefit within shareholders' firms. M\&A activity gives a potential value creation and offers some synergistic benefits for shareholders' merging companies.

The synergy then becomes the critical measure of successful performance after M\&A activity. Companies are so called successful in delivering $M \& A$ transaction if the new merged companies are able to show an improvement in their performance, greater profitability, and increment in shareholders firms' value as synergy hypothesis described.

To show whether the company is achieving the synergistic benefit which is expected to grow after M\&A transaction, the author considers examines some literature reviews to observe the performance after M\&A activity.

\subsubsection{Empirical Evidence of M\&A}

There are some studies that evaluated the performance after M\&A activity to see whether the companies are able to achieve the objective of M\&A in which the synergy becomes a main motive.

The studies showed a high number of failures in achieving the synergistic objective or increment in shareholders' value of M\&A transaction, such as:

a. Mercer Management Consulting (1997 and 1998): They evaluated the percentage of deals that achieve above industry 
shareholder returns over a 3 year period. The study used 215 transactions valued at $\$ 500$ million or more and the result showed at 1980 s $63 \%$ of failure and at 1990s $48 \%$ of failure to achieve above industry shareholder returns over a 3 year period. It is showed that the mergers of the 1990s are substantially outperforming those of the 1980s where the improvement was not related to strategy or price, but rather to the improvement of post M\&A management engaged in a compelling, ambitious vision, understood and shared by shareholders and management alive; a pragmatic approach to the alignment fall the pieces with the vision-organization structures, processes, systems and culture; and a plan for a fast and focused transition.

b.KPMG (1999): They investigated the percentage of deals that failed to increase shareholders value which is measured against a change in equity price pre-deal and in approximately 1 year after. The study used 107 companies that were involved in a major deal between 1996 and 1998, the result showed $83 \%$ of failure. The study found that successful deals engaged in a combination of the following key best practices: synergy evaluation, integration project planning, due diligence, selecting the management team, resolving cultural issues, and communications. Furthermore, the study also found that chance of success increased for companies that undertook a combination of these practices early in the deal.

Using similar measurement of change in equity price pre-deal and in approximately 1 year after, KPMG did a research in 2001 to measure the percentage of deals that failed to meet the success criteria: The sample used 118 companies involved in a major deal between 1997 and 1999 where the result showed $70 \%$ of failure and the study found that the successful deals used a robust and a well-managed process, priorities' allocation of activities which are going to be carried out, and clear decisions about how and by whom the activities should be handled.

c. McKinsey (2000): They investigated the percentage of deals that failed to meet the success criteria from 47 companies involved in major deals between 1997 and 1999. The result showed $65 \%$ of failure to meet the criteria for success of change in performance ethic profile, and improvement in a combination of market indicators (share price, analyst opinion, and revenue growth). The study found that failures were due to significant dilution of performance ethic, poor implementation, and loss of key people where the characteristics of successful mergers are strength of performance ethic, quick implementation, retention of key people, targets achieve, and positive market indicator.

d.AT Kearney (2000): They evaluated percentage of companies who showed an increment in shareholder value and profitability over a 3 year period post M\&A. The study found that $58 \%$ of all mergers failed to reach the goals they set out to achieve an improvement in stock prices and profitability where the issues were included failure to put corporate vision first, failure to move quickly enough in establishing leadership team, overemphasis on cost cutting versus growth, failure to overcome cultural differences, failure to communicate, and failure to manage risk.

From the literature reviews above, it was shown that mostly M\&A activity failed to meet the objective of M\&A transaction with a quite significant failure rate that is above $50 \%$ of overall transaction. The soft factor issues, such as cultural clash, resistance of change, communication, 
unwanted turnover, productivity decline, clarity of process, lack of consideration to implement cultural due diligence also to involve $\mathrm{HR}$ in the beginning of $\mathrm{M} \& \mathrm{~A}$ process, and unmanaged change transition in fast and quick post M\&A management are the major causes of significant failure rate. Managing soft factor issues should be included as a factor in calculating the integration cost to estimate the real overall valuation of company. That consideration will be useful to avoid losing the synergy benefit.

In overall the main reason of failure in M\&A is lack of the leadership role in managing the soft factor issues during M\&A preparation, integration, and implementation phase.

\subsubsection{M\&A Milestones}

The author here considers M\&A process key milestones on a sell side auction as below (Figure 4.):

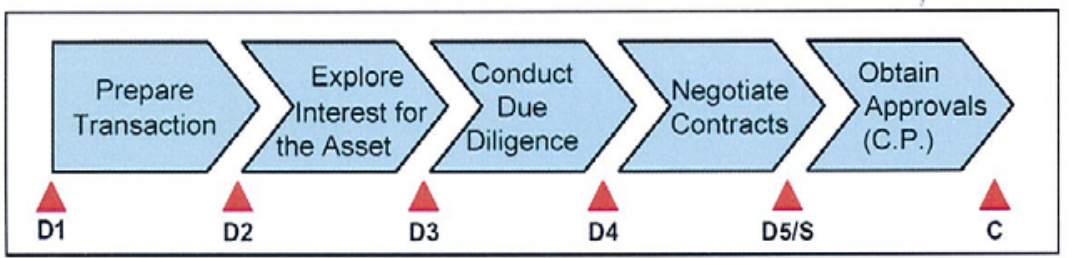

Source : Frank Richter (2007)

Figure 4.

M\&A Process Key Milestones

From figure 4. above, after obtaining approvals, the process will proceed to closing of transaction. That phase will be mainly focused on post M\&A integration and implementation phase of M\&A activity. In this article, the author mainly focuses on the post M\&A integration process including any aspects inside the phase that give a contribution in creating a smooth and fast transition integration process.

Based on literature reviews of empirical evidence M\&A, it was shown that some of causes of M\&A failure are related to insufficient information of potential knowledge and risk transfer of merging firms in which this information might be important in terms of managing the integration phase, and another cause is related to overestimation of revenue and synergistic benefit from M\&A transaction. Due diligence might be useful in mitigating and preventing those causes above by providing an initial deterrence of potential risk. Therefore, the author in this article puts on emphasis on HR due diligence as a part of leadership role in managing soft factor issues in M\&A activity.

\subsection{Aspects Of Leadership}

Leadership is "a set of processes that creates organizations in the first place or adapts them to significantly changing circumstances and defines what the future should look like, aligns people with that vision, and inspires to achieve it despite the obstacles”. Leadership is defined as a province of art in management and is more likely to be about people: knowing them; respecting them; respecting their individuality; and bringing them towards the conclusion that they are working for their own best interest when they give their best to 
the team. Leadership can also be defined as the ability to influence a group towards the achievement of the goals. It has an image of mobilizing people to tackle tough problem. The success of an organization depends on both effectiveness of management and leadership. Management and leadership terms cannot be separated, but should be solidified and act as a complement even though they subject to different focus and risk preferences.

To achieve the optimum performance of post M\&A integration, despite demonstrating a good management in managing daily procedures and process functions, leadership should be also considered as a key factor for post M\&A process in the terms of coping and nurturing the change. Leadership also acts as a change initiator, plays an important role in the beginning of change at creating and communicating new shared values and also in handling the human side or soft factor issues of M\&A integration process.

In this article, the aspects of leadership will be mainly focused on model or framework of organizational and integration of culture and change related to post M\&A process. The analysis will emphasize on HR due diligence as methodical investigation of management teamwork, staff, structure, and managerial capacity of merging companies that forms into a systematic observation related to potential value creation and risk of M\&A. The analysis will also cover the cultural integration strategy in post M\&A process as it needs an intensive effort and longer implementation related to a higher degree of difficult of implementation process. The cultural integration process will be based on the cultural assessment from HR due diligence process. The illustration of case study of LSG and Sky Chefs Inc will show that the successful integration requires leadership as a foundation to build a solid execution of post M\&A integration projects in how they planned, communicated, and delivered the objectives of the projects. The analysis of M\&A and leadership aspects will be main factor in determining the critical success factors of M\&A and the relation or linkage between leadership and M\&A activities.

\subsection{HR Due Diligence}

$\mathrm{HR} /$ Cultural due diligence is a diagnostic process conducted to ascertain the degree of cultural alignment or compatibility between companies that are party to a merger of acquisition. It is useful to measure the compatibility level within potential merging companies, and can also be a major consideration in selecting the potential interested parties.

The Table 1 . below consists of the critical HR/soft factor issues or compatibility issues with their impacts to the transactions process and also the types of documents needed to be observed by HR due diligence.

Table 1.

Critical HR Issues to Examine During Due Diligence

\begin{tabular}{|l|l|l|}
\hline \multicolumn{1}{|c|}{ Issue } & \multicolumn{1}{|c|}{ Impact } & \multicolumn{1}{|c|}{ Documents to examine } \\
\hline Organizational & Cultural differences most often have a significant & a. Customer lawsuits \\
culture & impact on integration, but only in rare situations is a & b. Employee lawsuits \\
& "show stopper" or have an impact on price. In those & c. Industry/governmental audits \\
& $\begin{array}{l}\text { situations, where culture has been the deciding factor on } \\
\text { stoppping a deal, it is typically a result of senior }\end{array}$ & d. Employee surveys \\
& $\begin{array}{l}\text { leadership incompatibility or indications of strong } \\
\text { differences in ethics/value systems. }\end{array}$ & f. Grievance reports \\
\hline
\end{tabular}




\begin{tabular}{|c|c|c|}
\hline $\begin{array}{l}\text { Employment } \\
\text { practices }\end{array}$ & $\begin{array}{l}\text { Excessive problems discovered around HR policies and } \\
\text { practices on the surface can portend much more } \\
\text { significant problem underneath. The number and type } \\
\text { of employee lawsuits (both closed and active), } \\
\text { grievances, work stoppages, and negative audits results } \\
\text { all can be indicators of much deeper problem. }\end{array}$ & Same as above \\
\hline $\begin{array}{l}\text { Health and } \\
\text { welfare } \\
\text { benefits }\end{array}$ & $\begin{array}{l}\text { The currency of insurance premiums; accruals for } \\
\text { medical, dental, sick pay, vacation, etc; and reserves for } \\
\text { incurred but unpaid claims (medical, dental, short term } \\
\text { disability, and other self-funded plans) can have a } \\
\text { material financial impact. }\end{array}$ & $\begin{array}{l}\text { a. Plans documents } \\
\text { b. Financial reports from third } \\
\text { party administration or } \\
\text { carriers }\end{array}$ \\
\hline $\begin{array}{l}\text { Retirement } \\
\text { benefits }\end{array}$ & $\begin{array}{l}\text { Unfunded obligations of current, frozen, or terminated } \\
\text { pension plans can be significant, including situations } \\
\text { where the plan financial obligations exceed the value of } \\
\text { the deal. In addition, the unfunded employer } \\
\text { cantribution for a defined contibution plan can present } \\
\text { both a significant financial obligation and a compliance } \\
\text { issue. }\end{array}$ & $\begin{array}{l}\text { a. Defined benefit plan } \\
\text { document } \\
\text { b. Most recent actuarial } \\
\text { valuation } \\
\text { c. Trust statement }\end{array}$ \\
\hline $\begin{array}{l}\text { Compensation } \\
\text { commitments } \\
\text { and } \\
\text { compliance }\end{array}$ & $\begin{array}{l}\text { It is important to quantify existing and future } \\
\text { compensation commitments. Expenses for } \\
\text { commissions, incentives, bonuses, etc., can be both } \\
\text { significant an unpredictable. It is also critical to } \\
\text { examine compliance with FLSA job classification of } \\
\text { exempt/nonexempt positions, as FLSA violations can } \\
\text { result in significant back pay and fines. }\end{array}$ & $\begin{array}{l}\text { a. Variable pay and retention } \\
\text { program plan documents } \\
\text { associated communications } \\
\text { b. FLSA policy manual }\end{array}$ \\
\hline $\begin{array}{l}\text { Executive } \\
\text { change-in- } \\
\text { control } \\
\text { provision }\end{array}$ & $\begin{array}{l}\text { Significant or excessive severance/change-in-control } \\
\text { payments could trigger excessive costs in absolute } \\
\text { terms or in terms of percetage of market capitalization, } \\
\text { as well as potential image issues. In some } \\
\text { circumstances, the magnitude of } 280 \mathrm{G} \text { gross-ups may } \\
\text { stop the deal. }\end{array}$ & $\begin{array}{l}\text { a. Deferred compensation plan } \\
\text { documents } \\
\text { b. Executive contracts Change- } \\
\text { in-control Agreements, } \\
\text { Broad-based severance plan, } \\
\text { Stock option plan/agreements } \\
\text { and data }\end{array}$ \\
\hline
\end{tabular}

Source : Robert A. Bundy (2005)

To do the cultural assessment, the author considers a framework of cultural assessment from J. Robert Carleton and Claude S. Lineberry (2004). 


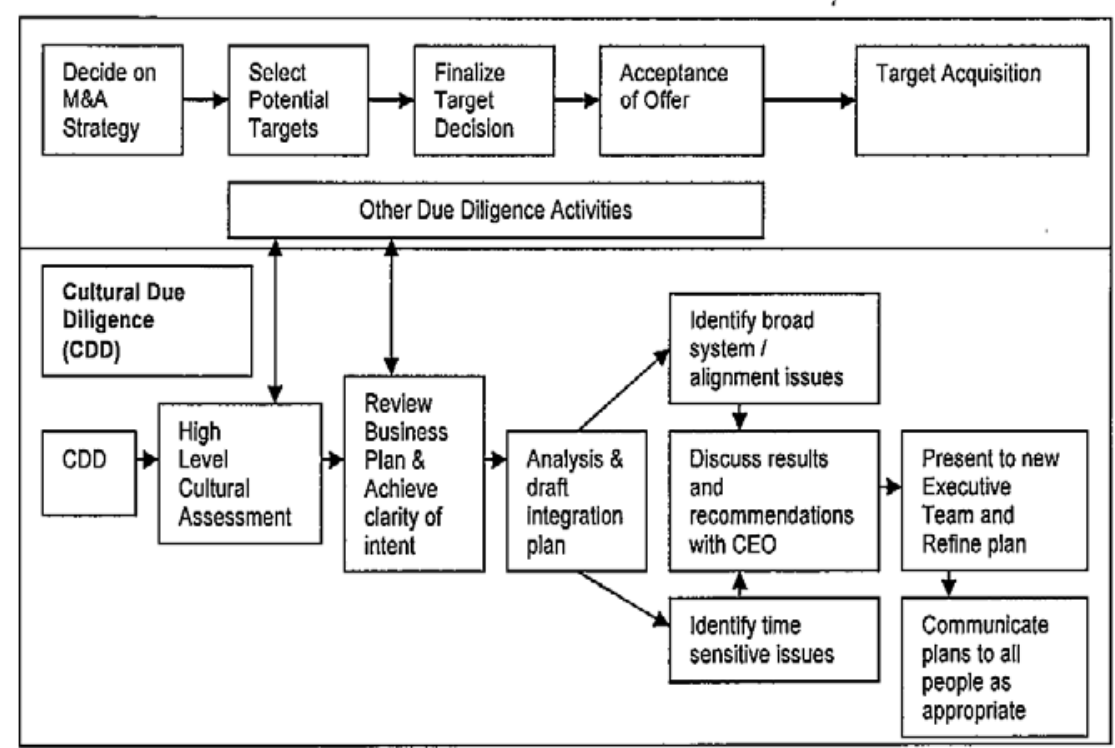

Source : Modified from J. Robert Carleton and Claude S. Lineberry (2004)

Figure 5.

Cultural Assessment

Based on the Figure 5. above, the due diligence is done after companies decide M\&A strategy, and within the phase of selecting potential interested parties, finalizing target decision, and accepting of an offer or as in Figure 4. is after explore interest for the asset phase. The cultural due diligence is conducted as part of other due diligence of hard factors analysis activities by reviewing some internal documentations such as retention and company's history, employees' survey, and company's intent. Despite analyzing those documents, the observation can also be formed in customized assessment, such as a quantitative survey of soft factor attributes. The survey itself will be a systematic observation formed to identify and profile the characteristic of soft factors' domains. The domains consist of intended direction and results, key measures, key business drivers, infrastructure, organizational practices, leadership/management practices, supervisory practices, work practices, technology use, physical environment, perceptions and expectations, and cultural indicators and artifacts. However, to have a more exquisite assessment, in depth interview with key executives, management presentation, and site observations can also be considered important.

Then, after gathering and estimating key people issues, risks, and also potential compatibility benefits of new merged companies, those findings will be analyzed and translated into integration planning draft. The integration planning also considers the alignment issues or degree of relatedness with potential merging companies, and also the time commitment of integration. The comprehensive integration planning will be reviewed with Chief Executive Officer (CEO). Those reviews and feedbacks will become major consideration for key executives in refining the integration strategy to win the merger. The remit of HR audit 
within overall due diligence process can serve as an initial precaution to determine the effects of a takeover on employees, and to analyze and assess existing HR assets. The final step of cultural due diligence is to communicate strategy merger plan to all employees as discussed as part of steps in post M\&A integration.

\subsection{Post M\&A Integration}

Post M\&A integration is the important process in overall M\&A activity, without a good preparation and a deep understanding of overall integration task, M\&A transaction will result in bad performances then will affect in financial and synergistic benefits of M\&A. A study by A.T. Kearney 1998 showed that 49\% of weighted success factors in the entire merger process are in post M\&A integration. Despite, increasing synergies as a realization of hard factors, the major focus in post $M \& A$ integration is related to managing soft factor issues which remain as the hardest one such as the integration of cultures and the coordination of all processes and systems inside the cultures. Companies should determine the type of cultural integration they want to build around by considering the strength and weakness from each company. Integration strategy and the implementation planning will be based on type of cultural integration that they choose to pursue.

\subsection{Cultural Integration Strategy}

There are three different strategies for cultural integration:

a.Monoculture strategy where the larger corporation more or less superimposes its corporate culture on smaller corporation in a kind of 'cultural colonization'.

b.Multiculture strategy where the acquisition retains its own culture, the resulting peaceful coexistence is rated positively and viewed as enrichment. c. Mixed culture strategy where both corporations merge into one, and the workplace is combined, a new, joint culture develops that is supported by everyone.

The cultural imposition as in monoculture strategy may lead to high resistance from employees and somehow destroye the value of the merger. In this strategy despite imposing the culture, to minimize the effect of disruption, the company should consider the importance of managing other potential soft factor issues such as communication and management style issue. According to A.T. Kearney research study, it is a problem in many mergers that the more powerful partner imposes his culture on the less powerful one, especially when both partners are very different; it needs a closer evaluation, which culture will be best for both together.

Multiculture strategy may work if merging companies have less similarity in scope of business or have different patterns in industries activities. They prefer to retain their own culture, so each company may perform their normal work pace without any interference or change from other company. Multiculture strategy may work if the major motive is a growth strategy, and the M\&A is done with a small or new company. Variety of culture is expected to give potential added value of shareholders' companies. Differences can be valued as a potential source of synergy.

Although in monoculture strategy the stronger company will impose the culture to the weaker company and in multiculture strategy, each company will retain its own culture, those cultural integration strategies will result in developing shared corporate values incorporated with a new vision, mission, value statements and company's code of conduct. Those also require a proactive change management process. 
The most common cultural integration is in a mixed culture strategy, this happens usually in horizontal mergers or merger of equals. The integration strategy will result in setting up new cultures. New merged company will have a new culture with new feasible vision, mission, and shared values aligned with structure, systems, strategic direction which expected to be realized from $M \& A$ activity. This strategy mostly focuses on fit approach within merging companies, and the strategy to capture and compound their best practices. Merging companies are aware of the differences within inherited cultures and use the differences as a basis to create new culture that give the new company high competitiveness edge in business position. The author emphasizes here on mixed culture strategy because this integration strategy needs an intensive effort and longer implementation related to a higher degree of difficulty. Another reason is although the mixed culture strategy has a higher difficulty in implementation process, the mixed culture strategy is an ideal integration strategy which pledges better achievement in future M\&A related to the balancing best elements from merging companies.

This has also been invigorated by some recent conceptualizations of integration as described below:

a. Integration is a more complex and interactive mutual adjustment between two organizations.

b.Integration requires more of a facilitated dialogue than a linear, unilaterally directed change process initiated by the acquiring organization to gain administrative control.

c. Integration requires a significant change on the part of the acquiring organization as well as by the acquired organization.

d.The mutual adjustment conceptualization of integration takes into account the relative difficulties of managing a range of degrees of boundary disruption, which may be managerially more difficult to implement than either a largely hands-off or an all-encompassing approach, because it implies the need for selectivity and restraint on the part of the acquirer.

The mixed culture strategy needs a manageable change process to cover the whole objectives of M\&A. The new culture, vision, and any other alignment process are created by taking into account the recommendation from due diligence including HR due diligence.

\subsection{The Integration Steps}

In the integration phase which mostly focuses on mixed culture strategy, companies use the analysis and integration plan coming out from strategic due diligence. Strategic due diligence becomes an instrument to indicate the hard and soft factor issues in M\&A. The due diligence can be considered as start-up phase of integration. In this article, the author points out on HR due diligence as pre-initial analysis in managing soft factor issues. The soft factor analysis result will be integrated with the hard factors of company's strategic and organizational structure of M\&A transaction towards achieving overall M\&A objectives. Thus, due diligence will be a formal tool to assess the potential problems and preventive action of post M\&A integration. If the soft factor issues relating to the critical concerns in M\&A change such as culture disparity and any other alignment domains have already addressed early on since the phase process started, the technical issues such as framing the rewards system, integrating organizational structure and detailed functional platforms will have more time to be managed in post M\&A integration process.

The integration process as a whole can be divided into two phases, the first 
phase is design integration, which usually takes 2-3 months depending on the scope and complexity of the merger, and the second phase will be an executing integration which takes around 1-2 years. The refined integration plans from strategic due diligence contain the whole topics of post M\&A integration. In integration design phase, the whole topics related to issues in post M\&A integration should be prioritized using some evaluation criterion to derive the importance of the topics with their potential impacts, and also to fetch the level of decision making and reporting requirements for each topic. The result of the prioritization will be derived into post M\&A integration organization structure. The post M\&A integration structure consists of merger team where each team comprises of key executives, managers, and all employees from merging firms who handle the project topics.

The main points to be highly considered and managed in integration design in area of soft factor issues are:

a. Building a new vision which covers the whole objective of M\&A.

b.Determining the shared values and attribute cultures that companies want to build.

c. Seeking employment opportunities of company by identifying the composition of management structure and personnel capacities that the merged companies want to build. The merged companies should try to secure the high performing talent and minimize the redundant employees. As additional for creating new structure, despite on sourcing with existing personnel, the external hiring might be considered to maximize performance of new organization.

d.Deciding the new managerial and functional capabilities. The new platforms of HR function such as reward system should also be built as a critical point to ensure an effective integration process. It is designed and built by a group consisting of HR staff from whole merging companies by reviewing current company's practices and strategy integrated with the new objectives and formulated integration plan from merged companies. In the case of cross border M\&A, in designing the reward system, companies should also consider some regulations and policies from each country. Therefore, it might be applied by employees of each merging countries.

The main focus for the management is to retain key employees. It is in line with the findings of some studies that the retention level increases after M\&A activity and may destroy a substantial part of M\&A value.

There are some findings regarding the increment of retention level:

- Up to $50 \%$ of a target's management leaves the company in the first 3-5 years.

- In US companies, a much higher number of managers leave during the first 2-3 years after an acquisition than before the acquisition or in comparable companies.

- When no coordinated retention actions are taken, $47 \%$ of all senior managers leave within the first year of the acquisition. But the exodus doesn't stop there. Within the first 3 years, $72 \%$ end up heading for the door'.

e. Building a good communication strategy and create an open environment.

f. Building a realistic estimation of potential value creation.

g.Employing a strategic due diligence as a basis to employ an effective integration.

h.Building qualitative soft factors measurement and review based on business performance drivers to measure the success of integration, therefore the further improvement of post M\&A integration can be built. 
After setting the integration design, the next phase will be an integration execution. This phase is done to implement the detailed plans which have been set up in the integration design phase. The detailed plans should be communicated persuasively with all employees to reduce the rumor and ambiguity within employees. This stage will be formed in a large working change team where each team performs its project plans. Each team is being represented by a functional manager of each department such as corporate culture, human resources, and so forth. Those teams will work together in cross functional departments supervised by integration board projects. Ideally the integration board projects consist of the CEO and key executives from whole merging companies. The knowledge integration database should be created to facilitate in monitoring M\&A integration activities such as project integration improvement, and in simplifying information access for every members of project merger integration team. The knowledge database can be modeled in some form like knowledge management system or some IT assisted system.

\subsection{Case Example}

To see that leadership gives an important contribution in M\&A situations, the author gives a case example from industries' experience which successfully employ leadership as one of the key factors in their M\&A strategy.

The example is a cross border merger between a German company, Lufthansa Service GmbH (LSG) and a US company Sky Chefs. In this example, the author would like to give a case example of a successful acquisition based on a mixed culture strategy which is based on an article from Ravin Jesuthasan and Helmuth L. Uder: Sky Chefs started business as a subsidiary of American Airlines in 1943 which was sold in
1987 to a group consisting of its management and Onex Corp. LSG, as a subsidiary of Lufthansa Airlines, acquired a stake in the food service company in 1993 and by 2001, LSG purchased the whole Sky Chefs company and created the largest airline catering in the world. The integration process was started with a clear understanding of the current practices of both organizations and also cognition of existing state at other leading companies. They were primarily concerned with managing soft factor issues during and after integration by minimizing the discrepancy in structure and roles, cultures, total rewards, and measurement and alignment. The organization's strategic priorities and the culture it wanted to create became the major focus of integration activities. In the area of structure and roles, when LSG and Sky Chefs merged, they created five organizational levels ranging from individual flight kitchens through countries, areas (aggregations of countries), regions (e.g. North and South America) and global. By this structure, the functional role was linked to the geographic role. Despite internal hiring, the company also considered doing external hiring to get a high performing management structure. The company also created an open structure where executives at each level had the opportunity to participate in decision making at the upper level. In the area of culture, the organization highlighted the commonalities, strengths relative to the desired culture, and gaps that would need to be bridged. The communication of desired future culture was facilitated by the leaders using the media tools of public meetings, one-on-ones, and email statements. The organization tried to combine two different cultures to become one culture to support business principles and objectives. In the area of total rewards, the organization early on employed a process of inventorying its 
current reward programs. The inventory covered the differences between current reward systems, the potential image of barriers and gaps from business merging, the operational work and measurement methodology of each company's reward system. The overall rewards philosophy to drive the integration of two companies was formulated by combining best practices information and a well understanding of desired business strategy and culture. In the area of measurement and alignment, LSG Sky Chefs made a framework used to create a shared understanding of the key drivers of product quality. The company expanded the framework into two key HR processes of performance management and annual incentives to certify alignment between key business drivers and individual performances.

From the illustration of LSG and Sky Chefs case example, the author would like to show that both companies successfully employed the mixed culture strategy. The companies successfully shaped the new entity's culture which best accommodated both companies' practices. The author finds that they successfully combined two different companies to become one business platform. The companies also realized the obstacles coming from soft factor issues since the beginning of the process, and the companies tried to overwhelm the issues by imparting leadership in the early phase of transaction. The role of leadership was applied by involving $\mathrm{HR}$ in the beginning of the process. HR here did its task in the scope of HR due diligence to assess the potential compatibility of both companies. Leadership here also played a role as a key success factor of this cross border integration by managing soft factor issues and minimizing the disruption occurring in areas of structure and roles, culture, total rewards, and measurement and alignment. Both companies tried to employ leadership as a factor to combine both differences towards to strategic value creation of transaction and establishment of new shared practices and culture, and as a basis to give a deep understanding of the current rationale of each company. The case example also invigorates the author's suggestion of the important role of leadership in M\&A situations. That success story also becomes one of the author's considerations in determining the critical success factor of M\&A and the conclusion of relation and linkage between leadership and M\&A.

\subsection{Overall Critical Success Factor}

The author proposes some critical success factors related to achieving M\&A overall success which are described as:

a.Bold and strong leadership as guidance through the M\&A transition process.

Leadership as a key success factor will be a fundamental basis to achieve other critical success factors needed in achieving a totally successful M\&A transaction. Effective leadership can help to strive for the excellence of M\&A process. The author suggests that leadership should be imparted as a main key success factor which covers and acts as a key sound of other critical success factors of M\&A success which they are suggested to be considered necessary in M\&A transaction. The critical success factors consist of:

- A well-established plan in every phase of M\&A transaction to make a smoother transition.

- High involvement of all functional elements in all companies including HR in the whole process of transactions.

- Overall consideration of due diligence activities for screening potential synergy and as a basis for risk management. HR 
due diligence should also be considered as an important strategic contributor.

- Development of a feasible vision as guidance through the change and also shared values platform.

- Effective internal and external communication of transaction.

- Effective cultural integration and alignment strategy.

- Low complacency and high sense of urgency in M\&A change.

- A high caliber formation of new management capabilities and good management of retention issues.

- High people engagement and commitment level to the M\&A change.

- Development of good reward and performance system.

- Employment of workable and structural change management practices.

- Appointed leaders including CEO and key executives who have integrity, capability and readiness to lead the change, and also high performing team merger integration.

b. The author also suggests other key success factors despite leadership. They are development and execution of an effective post M\&A integration, which cover other critical factors of M\&A success in which the author suggests to be considered important to achieve an effective transaction as described below:

- Good integration planning process which represents fast and quick transition process.

- Clear M\&A objectives covering financial and others non-financial goals and exact determination of prioritization of those objectives.

- Realistic and objective assessment of real valuation of company including synergy benefit and cost of integration.
- Establishment of an effective post M\&A integration structure and synergy realization process.

- A smooth execution of integration using top-down approach and a technology system for knowledge sharing system, reporting requirements, and integrated communication system.

- Clarity of future contractual structure and future work relationship with external party such as supplier distributor, and so forth.

From the analysis of critical success factors above, it could be proposed that leadership and effective post M\&A integration are becoming the key success factors of overall M\&A transaction. The author concludes that both key factors are related and complement each other, and there is a relation and linkage between them in which bold and strong leadership is needed and useful to create effective post M\&A integration. Strong leadership should be implemented early on in the beginning of M\&A process where the precise implementation can be formed in HR due diligence. Leadership will help to ensure the preparation including the processes, methodology, and management behavior, are ready to generate the planned integration synergies. The author also concludes for the relation and linkage between leadership and M\&A that leadership should become the main consideration role after closing phase; leadership will help to mitigate the risk of dual organization and management and to keep the business of both companies performing well during the transition period from old business framework to new reengineered framework. 


\subsection{The Best Characteristic and The Effectiveness Level of Leadership in $M$ \& $A$}

From the previous analysis of relation and linkage between leadership, the author derives a main conclusion that leadership plays a main role in M\&A process from the early phase of transaction to post closing phase in terms of building an effective transaction. The focal point of leadership implementation is laid on leader leverage capabilities. The author identifies and suggests several characteristics that leader should have to enhance M\&A outcomes, which are:

a. Leader should be able to persuade others to be committed and confided in M\&A change and identified the alignment issues before the shift transition.
b.Leader should be able to manage the emotional change pattern of employees. The emotional phase relates with resistance to change, internal stress, and competition fear.

c. Leader should have appropriate skills and behaviors set to pursue the change process.

d.Leader should be able to be a knowledge source of ideas, information, and reporting person of M\&A and also a role model for the change.

e. Leader should be able to institute the change process and naturalizing change.

To manage the M\&A change process, the author proposes that the characteristic of leader should be based on the ten commitments of leadership from James M. Kouzes (Table 2.).

Table 2.

Ten Commitments of Leadership

\begin{tabular}{|l|l|}
\hline \multicolumn{1}{|c|}{ Practices } & \multicolumn{1}{|c|}{ Commitments } \\
\hline Challenging the Process & $\begin{array}{l}\text { 1. Search out challenging opportunities to change, grow, innovative, and } \\
\text { improve. } \\
\text { 2. Experiment, take risks, and learn from the accompanying mistakes. }\end{array}$ \\
\hline Inspiring a Shared Vision & $\begin{array}{l}\text { 3. Envisions an uplifting and ennobling future. } \\
\text { 4. Enlist others in a common visions by appealing to their values, } \\
\text { interests, hopes and dreams. }\end{array}$ \\
\hline Enabling Others to Act & $\begin{array}{l}\text { 5. Foster collaboration by promoting cooperative goals and building } \\
\text { trust. }\end{array}$ \\
$\begin{array}{l}\text { 6. Streghten people by giving power away, providing choice, developing } \\
\text { competence, assigning critical tasks, and offering visible support. }\end{array}$ \\
\hline $\begin{array}{l}\text { 7. Set the example by behaving in ways that are consistent with shared } \\
\text { values. }\end{array}$ \\
8. Achieve small wins that promote consistent progress and build \\
commitment.
\end{tabular}

Source : James M. Kouzes and Barry Z. Posner (1995)

In those practices, the author concludes that they cover the characteristic behaviors that leader should have in managing the M\&A change transition. By these ten commitments of leadership model, the leader can propel the sense of urgency, trust foundation and embrace sense of accountability.

To see the effectiveness level of leadership, the author considers some measurement level of leadership effectiveness such as surveys and questionnaires, interviews to internal 
management and external stakeholders, HR performance measures, and organizational satisfaction measure.

It is also important to consider the use of performance measurement such as 360 degree feedback to measure the leadership performance in post M\&A integration to elicit the improvement for leadership implementation in managing the area of soft factors issues. 360degree feedback is the process of eliciting input regarding the strengths and weaknesses (areas in need of focus for improvement) from overhead, direct reports, colleagues and other important persons who can speak knowledgeably.

The consideration of the merged company to include the performance measures of change improvement in area of soft factor issues as a part of assessment of post M\&A integration transformation phase can be also considered important. It will form qualitative measures of how leadership addresses and facilitates in the change process. The performance measures can be seen in management behaviors in the reintegration into day to day business.

It can be suggested for the consideration of implementing post M\&A audit to measure the leadership performance related to people management factors in intervening M\&A process using the balance scorecard concept. The balanced scorecard is a management system (not only a measurement system) that enables organizations to clarify their vision and strategy and translate them into action and provides perspectives in learning and growth business process, customer, and financial area. For post M\&A integration, the area related to leadership action in managing the soft factor issues in post M\&A integration is mostly related to area perspectives of learning and growth, customer, and internal business process. The learning and growth will be mainly associated with corporate culture improvement and learning process ability for company in adapting the post M\&A integration. The internal business process will focus on how to measure post M\&A integration in conforming the people knowledge company's asset. The customer perspectives will be focused on measuring the performance relationship with customer after integration process.

\section{CONCLUSION}

From literature reviews of M\&A, it is identified that many M\&A transactions failed because of a lack of consideration of potential soft problems. In post M\&A integration, there is propensity that major considerations are in hard factors, in terms of synergy realization. To achieve a successful transaction, the attention to the hard factors is not sufficient. There should be integration between soft factors and hard factors as drawn in 7s McKinsey framework.

The hard factors in M\&A are related to development strategy, standard operating procedure or code of conduct, and management structure. The soft factors are related to development of company's shared values, communication management, cultural alignment, and employees' behaviors. A precise knowledge of soft factors from each merging partner is needed to enhance the acceptance of the deal and lower potential risks during the post M\&A integration execution stage.

The author concludes that leadership in M\&A solidified with management can give a positive difference in M\&A performance and is useful to create effective post M\&A integration.

The author also finds and proposes that leadership gives some positive impacts in M\&A: 
a. Leadership will help build a sense of urgency to drive the change, establishing directions for some strategic decisions, creating a sense of togetherness and aligning people to work on the change, and also building enthusiasm to deal with the barriers of change.

b.Leadership plays a role early in the beginning of the transaction in the due diligence phase which is used to evaluate the readiness and compatibility level of management potential partner in integration phase.

c. Leadership also plays a role as a fundamental framework for managing the change. The author proposes a workable planned change framework as a step to create useful change where in one of the detailed phase is manage the transition, the author emphasizes that phase as a critical part, and to create an effective transition, the author proposes a model of exemplary leadership from James M. Kouzes of ten commitments of leadership which consists all aspects needed to cope with M\&A change. An effective leader with leverage capabilities and skills to pursue the change will help to foster M\&A success.

d.To measure the effectiveness performance of leadership in post M\&A integration, the author considers some measurement level of leadership effectiveness such as internal organizational satisfaction measure, 360 degree feedback, and balance scorecard as a useful method in post M\&A audit.

\section{RECOMMENDATION}

The key finding of this research is that leadership in M\&A is important and can give a significant impact to a successful transaction. Managing M\&A should become a core competency for HR department. Companies with M\&A as their future strategy should evaluate their past experiences in managing M\&A deal. The evaluation should aim on how to deal with insufficient information during $\mathrm{HR}$ due diligence and how to deal with cultural integration bottlenecks. However, the author suggests that leadership should not be a general purpose excuse of failure.

If a company insists on the lack of leadership as the main reason of failure, there will be a lack of failure responsibility from employees. It occurs because of the assumption that organizational culture cannot be managed and should be taken as an inherited factor. 
Leadership in Merger ... (Lufina Mahadewi)

\section{BIBLIOGRAPHY}

Bentley, Timothy and Esther Kohn-Bentley. 2002. Leadership Coaching for the Workplace. New York: Irwin Publising

Carleton, J. Robert and Claude S. Lineberry. 2004. Achieving Post-Merger Success : a Stakeholder's Guide to Cultural Due Diligence, Assessment, and Integration. San Fransisco: Pfeiffer.

Deans, Greame K, Fritz Kroeger, and Stefan Zeisel .2003. Winning the Merger Endgame a Playbook for Profiting from Industry Consolidation. New York: McGraw-Hill.

Eun, Cheol S., Richard Kolodny, and C. Scheraga. 1996. "Cross-Border Acqusitions and Shareholder Wealth: Tests of the Synergy and Internalization Hypotheses”. In: Journal of Banking and Finance 20.

Frank $2007 . \quad$ Richter. "Investment Banking Part 2: M\&AAdvisory”.http://www.mathematik.uniulm.de/strategie/Lehre/SSO7/Investmentbanking_SS07/ part 2.pdf. Accessed on 3 June 2007.

Halil Kiymaz and H. Kent Baker. 2004. "Do Megamergers Create Value". http://www.fma.org/Chicago/Papers/Megamergers.pdf. Accessed on 5 July 2007.

Heifetz, Ronald A. 1998. Leadership Without Easy Answers (Hardcover). Cambridge, Massachusetts, London, England: Belknap Press The Belknap Press of Harvard University Press

Hermsen, C. 1994. Mergers \& Acquisitions - Integrations management von Akquisitionens objekten. Hallstadt.

Hubbard, N. 1999. Acquisition: Strategy and Implementation. London: Macmillan Press.

Kaplan, Robert S. and David P. Norton. 1996. Balanced Scorecard, The (Hardcover). New York: McGrawHill.

Koch, Thomas. 2002. "Post-Merger Integration”. In: Picot, Gerhard, ed: Handbook of International Mergers and Acquisitions: Planning, Execution and Integration (Hardcover). New York: Palgrave Macmillan.

Kotter, John P. 1996. Leading Change (Hardcover). Boston: Harvard Business School Press.

Kouzes, James M. and Barry Z. Posner. 1995. The Leadership Challenge, 4th Edition (Hardcover). San Fransisco: Jossey-Bass.

Lucks, Kai. 2005. Transatlantic Mergers And Acquisitions: Opportunities And Pitfalls in German-American Partnerships. Munich: Wiley.

Michael J. Shelton-FTC Bureau of Economics Roundtable. 2002. "Understanding Mergers: Strategy \& Planning, Implementation, and Outcomes".http://www.ftc.gov/be/rt/presentationpanels1thru5.pdf. Accessed on 27 June 2007.

Mulherin, J. H. and A. L. Boone. 2000. “Comparing acquisitions and divestitures”. In: Journal of Corporate Finance 6.

Pablo, A.L. 1994. "Determinants of acquisition integration level: A decision-making perspective". In: Academy of Management Journal 37(4).

Picot, Gerhard. 2002. Handbook of International Mergers and Acquisitions: Planning, Execution and Integration (Hardcover). New York: Palgrave Macmillan.

Pritchett, P. 1997. After the Merger. New York: McGraw-Hill.

Recklies, Oliver. 2001. "Mergers and Corporate Culture".http://www.themanager.org/pdf/Merger_Culture.PDF. Accessed on 19 June 2007.

Robert A. Bundy. 2005. "Making the most of M\&A Due Diligence; Paving the Way for a Smoother, Faster Integration". http://mercerghsc.com/summary.jhtml/dynamic/idContent/. Accessed on 27 June 2007.

Robbins, P. Stephen. 2003. Organizational Behavior. NJ: Prentice Hall

Seth, Anuj, Kean P. Song, and Richardson Pettit. 2000. "Synergy, Managerialism or Hubris? An Empirical Examination of Motives for Foreign Acqusition of U.S. Firms". In: Journal of International Business Studies 31 (No. 3, $3^{\text {rd }}$ Quarterly). 
Sewing, N. 1996. Akquisition erfolg durch Integration der Mitarbeiter. Wiesbader.

Sim B. Sitkin and Amy L. Pablo. 2004. "The Neglected Importance of Leadership in Mergers and Acquistions”. http://faculty.fuqua.duke.edu/. Accessed on 27 June 2007.

Tani, Andrew EB. 2002. Get Real: Empower The Manager-Leader Within. Boston: McGraw-Hill.

Waterman, Robert H., Jr., Thomas J. Peters and Robert Waterman. 1988. In Search of Excellence: Lessons from Americas Best Run Companies (Paperback). New York: Grand Central Publishing. 